RESEARCH REPORT

\title{
Can social factors explain sex differences in insomnia? Findings from a National Survey in Taiwan
}

\author{
Ying-Yeh Chen, Ichiro Kawachi, S V Subramanian, Dolores Acevedo-Garcia, Yue-Joe Lee
}

J Epidemiol Community Health 2005;59:488-494. doi: 10.1136/jech.2004.02051 1

See end of article for authors' affiliations

Correspondence to:

Dr Y-Y Chen, Taipei City

Psychiatric Centre, 309

Songde Road., Xinyi

District, Taipei City 110,

Taiwan; ychen@hsph.

harvard.edu

Accepted for publication 22 November 2004

\begin{abstract}
Study objective: To examine sociological explanations for the higher level of insomnia in women, including social roles and socioeconomic status (SES).

Design: Cross sectional survey research

Setting: Taiwanese 2001 "social trend survey"

Participants: A nationally representative sample of 39588 citizens aged 15 years or older living in Taiwan.

Main results: On average, women scored 1.25 points higher than men on the insomnia inventory $(p<0.001)$ but after controlling for social roles, the sex discrepancy in insomnia decreased slightly. SES did not, however, explain women's higher levels of insomnia. Subscale analysis showed an association between the role of homemaker and increased night time sleep disturbance and decreased daytime sequelae of poor sleep while higher educational attainment was related only to more severe daytime sequelae.

Conclusion: The sex discrepancy in insomnia narrowed slightly after taking social role factors into consideration but was not explained by SES. The persistent sex gap in insomnia warrants further investigation.
\end{abstract}

A female excess in the prevalence of insomnia has been shown consistently across countries and cultures. ${ }^{1-3}$ Insomnia is 1.3 to 2.0 times more common in women than men but our understanding of this difference remains limited. ${ }^{125}$ Researchers have examined sex discrepancies in insomnia from three perspectives with different assumptions- biological, prior psychiatric illness, and sociological. ${ }^{6}$

The biological explanation posits that innate physiological differences between men and women are responsible for sex differences in sleep initiation, maintenance, and quality. ${ }^{7}$ Although past studies are not conclusive, a number of findings support this explanation. ${ }^{13}$ For example, sleep disturbance is one of the most common complaints among menopausal and peri-menopausal women, especially those with substantial menopausal syndromes such as hot flushes and heavy sweating. ${ }^{8}$ In addition, sex specific circadian rhythms in core body temperature have been shown to be related to sleep quality ${ }^{10}$ and female sex hormones to affect sleep by influencing GABA-ergic neurons. ${ }^{11}$ Other biological differences that may affect sleep include differences in slow wave sleep, sleep spindles, and menstrual cycle related body core temperature change. ${ }^{11} 12$

Minor mental disorders, commonly associated with sleep disturbance, are more common among women. ${ }^{14}$ However, at least one empirical study has shown that after adjusting for baseline depression and anxiety, sex differences in sleep quality remain. ${ }^{14}$ Thus, pre-existing psychiatric disorders cannot fully account for the observed sex discrepancies.

The sociological approach focuses on sex inequality in the division of household labour-for example, time use studies show that women are more likely to work double shifts and as a result, sleep for fewer hours than their male partners. ${ }^{15}$ In contrast with explanations emphasising sex differences in biology and prior psychiatric illnesses, the sociological perspective has not been well investigated in the existing literature.

The aim of this study was to situate sleep disturbance within the broader social context in Taiwan and to explore the social determinants of sex differences, particularly social roles and socioeconomic status (SES). There are clear sex differences in social roles with just $46 \%$ of women participating in the labour force, compared with $69 \%$ of men, and $25 \%$ of women reporting their occupation as fulltime homemaker. ${ }^{16}$ In addition, about one third of households are headed by women.

\section{METHODS}

\section{Study population}

Our analyses were based on a nationally representative sample of resident Taiwanese citizens aged 15 years (the 2001 social trend survey). ${ }^{17}$ The sampling frame was all registered households in the Department of Domicile Administration, a government organisation that registers information on births, deaths, marital status, and migration of household members. Stratified two stage clustered sampling was used. Neighbourhoods (the primary sampling unit) within each city were stratified based on population size, household number, age distribution, types of labour force participation, and level of urbanisation. Neighbourhoods in Taiwan contain between 1000 and 8000 people, and represent the basic administrative unit in that country. Neighbourhoods were randomly sampled from each stratum, and households within those neighbourhoods were randomly selected. The study population was all people over age 15 living in the sampled households. In total, there were 39681 people living in 13065 households nested within 871 neighbourhoods. After excluding subjects who were missing the outcome variable, the final sample size for analysis was 39588 (male: 20 107, female: 19 481). Trained interviewers collected information through face to face interviews. 
Table 1 Distribution of predictor variables and mean insomnia scores, by sex

\begin{tabular}{|c|c|c|c|c|c|c|c|c|c|}
\hline & \multicolumn{3}{|c|}{ Women $(n=19481)$} & \multicolumn{3}{|c|}{ Men $(n=20107)$} & \multicolumn{3}{|c|}{ Total $(n=39588)$} \\
\hline & Number (\%) & Mean & (SD) & Number (\%) & Mean & (SD) & Number (\%) & Mean & (SD) \\
\hline Insomnia score ${ }^{* \star *}$ & & 24.6 & (8.9) & & 22.9 & (8.3) & & 23.7 & (8.7) \\
\hline $\operatorname{Age}^{* \star}$ & & & & & & & & 41.9 & $(17.6)$ \\
\hline $15-25$ & $4200(21.6)$ & 22.0 & (8.0) & $4207(20.9)$ & 20.7 & (7.5) & $8407(21.2)$ & 21.3 & (7.8) \\
\hline $26-45$ & $7680(39.4)$ & 24.3 & (8.6) & $8261(41.1)$ & 22.7 & (8.1) & $15941(40.3)$ & 23.5 & (8.4) \\
\hline $46-65$ & $5192(26.7)$ & 25.6 & (9.0) & $5045(25.1)$ & 23.4 & (8.3) & $10237(25.9)$ & 24.5 & (8.7) \\
\hline$>65$ & $2409(12.4)$ & 28.3 & $(9.6)$ & $2594(12.9)$ & 25.8 & $(9.2)$ & $5003(12.6)$ & 27.0 & (9.5) \\
\hline \multicolumn{10}{|c|}{ Self assessed health ${ }^{* * *}$} \\
\hline Good & $8388(43.1)$ & 21.0 & (7.3) & $10659(53.0)$ & 20.2 & (6.9) & $19047(48.1)$ & 20.6 & (7.1) \\
\hline Fair & $8707(44.7)$ & 26.2 & (8.2) & $7368(36.6)$ & 24.7 & (8.1) & $16075(40.5)$ & 25.5 & (8.2) \\
\hline Poor & $2386(12.2)$ & 31.7 & (10.2) & $2080(10.3)$ & 29.8 & (10.1) & $4466(11.3)$ & 30.8 & $(10.2)$ \\
\hline \multicolumn{10}{|l|}{ Shift work ${ }^{* *}$} \\
\hline No & $17544(90.1)$ & 24.6 & (8.9) & $16992(84.5)$ & 22.7 & (8.3) & $34536(87.2)$ & 23.7 & (8.7) \\
\hline Yes & $1937(9.9)$ & 25.0 & (8.7) & $3115(15.5)$ & 23.6 & (8.4) & $5052(12.8)$ & 24.1 & (8.5) \\
\hline \multicolumn{10}{|l|}{ Marital status ${ }^{* \star *}$} \\
\hline Single & $5150(26.4)$ & 22.4 & (8.1) & $6713(33.4)$ & 21.3 & (7.9) & $11863(30.0)$ & 21.7 & (8.0) \\
\hline Married & $11812(60.6)$ & 25.0 & (8.9) & $12170(60.5)$ & 23.5 & $(8.4)$ & $23982(60.6)$ & 24.3 & (8.7) \\
\hline Divorced & $572(2.9)$ & 26.3 & (9.5) & $593(3.0)$ & 24.5 & $(9.0)$ & $1165(2.9)$ & 25.4 & (9.3) \\
\hline Widowed & $1947(10.0)$ & 27.5 & (9.3) & $631(3.1)$ & 25.80 & (9.1) & $2578(6.5)$ & 27.1 & (9.3) \\
\hline \multicolumn{10}{|l|}{ Employment $^{\star \star *}$} \\
\hline Employed & $7712(39.6)$ & 23.9 & (8.3) & $12839(63.9)$ & 22.4 & (7.9) & $20551(51.9)$ & 23.0 & $(8.1)$ \\
\hline Unemployed & $677(3.5)$ & 26.3 & (9.3) & $1229(6.1)$ & 24.2 & (9.3) & $1906(4.8)$ & 24.9 & (9.3) \\
\hline Others & $2127(10.9)$ & 28.7 & $(10.0)$ & $3522(17.5)$ & 25.8 & (9.5) & $5649(18.4)$ & 26.9 & $(9.8)$ \\
\hline Homemaker & $6918(35.5)$ & 24.9 & $(9.0)$ & $366(1.8)$ & 22.7 & $(8.4)$ & $7284(10.6)$ & 24.8 & (8.9) \\
\hline Student & $2047(10.5)$ & 21.3 & $(7.6)$ & $2151(10.7)$ & 20.2 & (7.1) & $4198(14.3)$ & 20.7 & (7.3) \\
\hline \multicolumn{10}{|l|}{ Number of children } \\
\hline$\leqslant 2$ & $17445(89.6)$ & 24.6 & (8.9) & $18124(90.1)$ & 22.8 & (8.3) & $35569(89.9)$ & 23.7 & (8.7) \\
\hline$>2$ & $2036(1.2)$ & 24.6 & (8.9) & $1983(9.9)$ & 23.2 & (8.5) & $4019(10.2)$ & 23.9 & (8.7) \\
\hline \multicolumn{10}{|l|}{ Educational level *** } \\
\hline$<9$ years & $6801(34.9)$ & 26.4 & (9.3) & $4752(23.6)$ & 24.5 & (9.1) & $11553(29.2)$ & 25.6 & (9.3) \\
\hline $9-11$ years & $2628(13.5)$ & 24.2 & (8.8) & $3599(17.9)$ & 22.9 & (8.4) & $6227(15.7)$ & 23.5 & (8.6) \\
\hline $12-15$ years & $5945(30.5)$ & 23.5 & $(8.6)$ & $6786(33.8)$ & 22.2 & (8.1) & $12731(32.2)$ & 22.8 & $(8.3)$ \\
\hline$\geqslant 16$ years & $4107(21.1)$ & 23.6 & $(8.1)$ & $4970(24.7)$ & 22.2 & (7.6) & $9077(22.9)$ & 22.8 & $(7.9)$ \\
\hline \multicolumn{10}{|l|}{ Personal income $e^{\star \star \star}$} \\
\hline No income & $8152(41.9)$ & 24.7 & (9.2) & $4129(20.5)$ & 22.6 & (8.9) & $12281(31.0)$ & 24.0 & $(9.1)$ \\
\hline$<\$ 8500$ & $5051(25.9)$ & 25.5 & (9.2) & $4057(20.2)$ & 24.2 & $(9.0)$ & $9108(37.3)$ & 24.9 & $(9.1)$ \\
\hline$\$ 8500-17000$ & $5526(28.4)$ & 23.7 & $(8.2)$ & $9228(45.9)$ & 22.4 & (7.9) & $14754(23.0)$ & 22.9 & $(8.0)$ \\
\hline$>\$ 17000$ & $752(3.9)$ & 25.0 & (8.1) & $2693(13.4)$ & 22.8 & (7.5) & $3445(8.7)$ & 23.3 & (7.7) \\
\hline \multicolumn{10}{|l|}{ Smoking status } \\
\hline Non-smoker & $18856(96.8)$ & 24.5 & (8.8) & $11308(56.2)$ & 22.5 & (8.3) & $30164(76.2)$ & 23.8 & (8.7) \\
\hline Smoker & $625(3.2)$ & 27.9 & (10.3) & $8799(43.8)$ & 23.3 & (8.4) & $9424(23.8)$ & 23.6 & (8.6) \\
\hline \multicolumn{10}{|l|}{ Regular exercise ${ }^{\star \star *}$} \\
\hline Regular & $6236(32.0)$ & 24.5 & (8.6) & $6739(33.5)$ & 22.5 & $(8.1)$ & $12975(32.8)$ & 23.5 & (8.4) \\
\hline Not regular & $13245(68.0)$ & 24.7 & $(9.0)$ & $13368(66.5)$ & 23.0 & (8.5) & $26613(67.2)$ & 23.9 & $(8.8)$ \\
\hline \multicolumn{10}{|l|}{ Betel nut use* } \\
\hline Non-user & $19062(97.9)$ & 24.6 & (8.9) & $14745(73.3)$ & 22.3 & (8.2) & $33807(85.4)$ & 23.6 & (8.6) \\
\hline User & $419(2.2)$ & 26.7 & (9.6) & $5362(26.7)$ & 24.5 & (8.6) & $5781(14.6)$ & 24.6 & (8.7) \\
\hline \multicolumn{10}{|l|}{$\mathrm{BMI}^{\star \star \star *}$} \\
\hline$<25$ & $16095(82.6)$ & 24.4 & (8.8) & $14717(73.2)$ & 22.7 & (8.3) & $30812(77.8)$ & 23.6 & $(8.6)$ \\
\hline $25-30$ & 2906 (14.9) & 25.5 & (9.2) & $4777(23.8)$ & 23.2 & (8.3) & $7683(19.4)$ & 24.1 & (8.7) \\
\hline$>30$ & $480(2.5)$ & 25.8 & (9.8) & $613(3.1)$ & 24.0 & (8.7) & $1093(2.8)$ & 24.8 & (9.2) \\
\hline
\end{tabular}

$t$ Test was used to compare means between two groups and one way analysis of variance was used to compare means between more than two groups. The comparisons were only made for the total sample. ${ }^{*} p<0.05,{ }^{* *} p<0.001,{ }^{* * *} p<0.0001$.

\section{Outcome variable}

The insomnia self assessment inventory is a 13 item self reported inventory designed by the WHO worldwide project on sleep and health that uses a five point Likert scale ( 1 never, 2 seldom, 3 sometimes, 4 usually, 5 all the time) to measure insomnia (see appendix for English version). ${ }^{18}$ The higher the score the more severe the insomnia.

The internal consistency reliability of the questionnaire measured by Cronbach's $\alpha$ was 0.91. A review of the correlations between items showed that item 7-I drink alcohol to help me fall asleep-had a low correlation with the total scale $(r=0.26)$ and it was therefore eliminated from the analysis, increasing the Cronbach's $\alpha$ to 0.92 .

The construct validity of the scale was shown by its association with self assessed health and was further supported by a factor analysis that showed two factor loadings. The first factor was related to night time sleep disturbance (items 1 to 6 , plus item 8); the second was correlated with daytime sequelae of poor sleep (items 9 to 13). These two dimensions are consistent with the DSM-IV definition and operalisation of insomnia. ${ }^{19}$

\section{Independent variables}

The conceptual framework for our analyses was based on a bio-psycho-social model of sex differences in insomnia. We introduced a succession of variables into our models to test whether they could explain the observed sex differences. The blocks of variables represent: (1) potential biological and behavioural mediators of sex differences in insomnia (body mass index, smoking, betel nut use, exercise); (2) potential social and psychosocial mediators of sex differences (social roles and SES); and (3) previously established predictors of insomnia (age, general health status, and involvement in shift work).

Social role

Woman's social roles, such as wife, employee, and mother, were operationalised by marital status, employment 
Table 2 Linear regression results showing sex difference in insomnia self assessment inventory score before and after adjusting for social roles and SES

\begin{tabular}{|c|c|c|c|c|c|c|c|c|c|c|c|c|c|c|}
\hline \multirow[b]{2}{*}{ Parameter } & \multicolumn{2}{|l|}{$\begin{array}{l}\text { Model } 1 \\
\text { (baseline) }\end{array}$} & \multicolumn{2}{|c|}{$\begin{array}{l}\text { Model } 2 \text { (baseline } \\
\text { model + marital } \\
\text { status) }\end{array}$} & \multicolumn{2}{|c|}{$\begin{array}{l}\text { Model } 3 \text { (baseline } \\
\text { model + } \\
\text { employment } \\
\text { status) }\end{array}$} & \multicolumn{2}{|c|}{$\begin{array}{l}\text { Model } 4 \text { (baseline } \\
\text { model + no. of kids } \\
\text { in the family) }\end{array}$} & \multicolumn{2}{|c|}{$\begin{array}{l}\text { Model } 5 \text { (baseline } \\
\text { model + } \\
\text { educational level) }\end{array}$} & \multicolumn{2}{|c|}{$\begin{array}{l}\text { Model } 6 \text { (baseline } \\
\text { model + } \\
\text { household } \\
\text { income) }\end{array}$} & \multicolumn{2}{|c|}{ Model 7 (full model) } \\
\hline & estimate & SE & estimate & SE & estimate & SE & estimate & SE & estimate & SE & estimate & SE & estimate & SE \\
\hline Intercept & 22.73 & $(0.24)$ & 22.90 & $(0.24)$ & 23.10 & $(0.25)$ & 22.51 & $(0.24)$ & 22.11 & $(0.28)$ & 22.73 & $(0.25)$ & 22.55 & $(0.31)$ \\
\hline Age & $0.04^{\star *}$ & $(0.00)$ & $0.01^{* *}$ & $(0.00)$ & $0.03^{* *}$ & $(0.00)$ & $0.04^{* *}$ & $(0.00)$ & $0.04^{\star \star}$ & $(0.00)$ & $0.03^{* *}$ & $(0.00)$ & $0.01^{* *}$ & $(0.00)$ \\
\hline \multicolumn{15}{|c|}{ Self assessed health (base-fair) } \\
\hline Healthy & $-3.82^{* *}$ & $(0.08)$ & $-3.83^{* *}$ & $(0.08)$ & -3.79 & (0.08) & $-3.83^{\star *}$ & (0.08) & $-3.85^{\star *}$ & (0.08) & $-3.83^{* *}$ & (0.08) & $-3.82^{\star *}$ & $(0.08)$ \\
\hline Unhealthy & $5.11^{* *}$ & $(0.12)$ & $5.25^{* *}$ & $(0.12)$ & 5.13 & $(0.13)$ & $5.13^{* *}$ & $(0.12)$ & $5.13^{* *}$ & $(0.12)$ & $5.12^{* *}$ & $(0.12)$ & $5.18^{* *}$ & $(0.13)$ \\
\hline \multicolumn{15}{|c|}{ Shift working (base-non shift) } \\
\hline Shift & $0.77^{* *}$ & $(0.11)$ & $0.64^{* *}$ & $(0.11)$ & 0.75 & $(0.11)$ & $0.75^{\star *}$ & $(0.11)$ & $0.75^{\star *}$ & $(0.11)$ & $0.77^{* *}$ & $(0.11)$ & $0.73^{* *}$ & $(0.11)$ \\
\hline \multicolumn{15}{|l|}{ Sex (base-male) } \\
\hline Female & $1.25^{\star *}$ & $(0.07)$ & $1.15^{\star *}$ & (0.07) & $1.24^{\star \star}$ & $(0.07)$ & $1.24^{\star \star}$ & (0.07) & $1.29^{* *}$ & $(0.07)$ & $1.25^{\star *}$ & $(0.06)$ & $1.22^{\star \star}$ & $(0.08)$ \\
\hline \multicolumn{15}{|l|}{ Marital status (base-single) } \\
\hline Married & & & $1.09 * *$ & $(0.10)$ & & & & & & & & & $1.05^{* *}$ & $(0.12)$ \\
\hline Divorced/separate & & & $1.61^{* *}$ & $(0.22)$ & & & & & & & & & $1.53^{* *}$ & $(0.23)$ \\
\hline Widowed & & & $1.29^{* *}$ & $(0.20)$ & & & & & & & & & $1.23^{* *}$ & $(0.20)$ \\
\hline \multicolumn{15}{|c|}{ Employment (base-employed) } \\
\hline Unemployment & & & & & $1.28^{* *}$ & $(0.17)$ & & & & & & & $1.46^{* *}$ & $(0.17)$ \\
\hline Disability/retired/others & & & & & $0.28^{*}$ & (0.13) & & & & & & & $0.53^{\star *}$ & $(0.14)$ \\
\hline Homemaker & & & & & 0.16 & $(0.11)$ & & & & & & & 0.14 & $(0.11)$ \\
\hline Student & & & & & $-0.97^{* *}$ & $(0.13)$ & & & & & & & $-0.56^{* *}$ & $(0.14)$ \\
\hline $\begin{array}{l}\text { Number of children in the } \\
\text { household }\end{array}$ & & & & & & & $0.25^{* *}$ & $(0.04)$ & & & & & $0.13^{*}$ & $(0.05)$ \\
\hline \multicolumn{15}{|c|}{ Educational level (base $-<9$ years) } \\
\hline Some high school & & & & & & & & & $0.25^{*}$ & $(0.12)$ & & & -0.05 & $(0.12)$ \\
\hline High school graduate & & & & & & & & & $0.44^{* *}$ & $(0.12)$ & & & $0.31^{*}$ & $(0.12)$ \\
\hline Some college or higher & & & & & & & & & $0.50^{* *}$ & $(0.13)$ & & & $0.53^{* *}$ & $(0.14)$ \\
\hline \multicolumn{15}{|c|}{$\begin{array}{l}\text { Income level (base-very low } \\
\text { income) }\end{array}$} \\
\hline Low income & & & & & & & & & & & -0.05 & $(0.12)$ & -0.11 & $(0.12)$ \\
\hline Middle income & & & & & & & & & & & 0.04 & (0.13) & -0.12 & $(0.14)$ \\
\hline High income & & & & & & & & & & & 0.38 & $(0.28)$ & 0.10 & $(0.29)$ \\
\hline
\end{tabular}

sttus, and number of household members aged less than 15 years. Marital status was grouped into never married, married, widowed, and divorced/separated. Employment status was recoded into five groups - employed (self employed or employed for wages), unemployed (unemployed and actively seeking work), homemaker (unpaid housekeeper), student and other (retiree, unemployed due to disability, or unemployed for unspecified reasons). The number of family members under age 15 was used as a proxy for childcare responsibilities and modelled as a continuous variable.

\section{Socioeconomic status}

SES was operationalised by household income and educational attainment. In the social trend survey, participants were asked to define their annual personal income from a list of nine categories: no income; <NT200 000; NT200 000299 999; NT300 000-399 999; NT400 000-599 999; NT600 000799 999; $\quad$ NT800 000-1 000 000; NT1 000 000-1499 999; $>$ NTI 500000 (\$1 equals to NT 34). Household income was constructed by assigning the midpoint of each personal income category as the value of individual income and summing the income of all household members. Household income was standardised to the number of adults in the household (that is, household income divided by the square root of total number of adults) to account for household size. Adjusted household income was then categorised in four levels: very low income $\leqslant \$ 8000$, low income \$8001-15 000, middle income \$15 001-30 000, and high income $>\$ 30000$.

Educational attainment was categorised into elementary education or lower, some high school, high school graduate, and some college or higher.

\section{Other covariates}

Age was modelled as a linear variable. Self assessed health was categorised as good, fair, and poor. Shift work status and health related behaviours (including cigarette smoking, betel nut use, and exercise) were modelled as binary parameters. Obesity (operationalised as body mass index (BMI)) was modelled in three categories: normal $\left(<25 \mathrm{~kg} / \mathrm{m}^{2}\right)$, overweight $\left(25-30 \mathrm{~kg} / \mathrm{m}^{2}\right)$, and obese $\left(>30 \mathrm{~kg} / \mathrm{m}^{2}\right)$.

\section{Analytical strategy}

To account for the design effect, MLwin software was used to adjust for intraclass correlation. Explanatory variables were added sequentially to an initial linear regression model that included (besides sex), age, self assessed health, and shift work status. Changes in the coefficient for sex were used to assess the effect of subsequently introduced variables on the sex discrepancy in insomnia. In addition, we also examined sex differences in subscales of the insomnia inventory (night time sleep disturbance compared with daytime sequelae of poor sleep). Lastly, we assessed interactions between sex and social factors. The three way interaction between SES, employment status, and family responsibilities (ever married and having children) was assessed using a stratified analysis of insomnia scores among women of childbearing age (20-45).

\section{RESULTS}

Table 1 shows crude associations between sociodemographic characteristics and insomnia score by sex. Overall, bivariate relations among men and women showed that insomnia was associated with older age, divorce/separation, less than high school education, low income, poor self assessed health, smoking, and betel nut use. Students and regular exercisers tended to have better sleep quality. 
Table 3 Linear regression results showing sex difference in insomnia, before and after adjusting for health related behaviours and BMI

\begin{tabular}{|c|c|c|c|c|c|c|c|c|c|c|c|c|}
\hline & \multicolumn{2}{|c|}{$\begin{array}{l}\text { Before adjusting for } \\
\text { behaviours and obesity }\end{array}$} & \multicolumn{2}{|c|}{ Control for smoking } & \multicolumn{2}{|c|}{ Control for exercise } & \multicolumn{2}{|c|}{$\begin{array}{l}\text { Control for betel nut } \\
\text { use }\end{array}$} & \multicolumn{2}{|c|}{ Control for BMI } & \multicolumn{2}{|c|}{ Full model } \\
\hline & estimate & SE & estimate & SE & estimate & SE & estimate & SE & estimate & SE & estimate & SE \\
\hline Intercept & 22.55 & (0.31) & 22.12 & (0.31) & 22.54 & $(0.31)$ & 21.97 & (0.31) & 22.57 & $(0.31)$ & 21.89 & (0.31) \\
\hline Age & $0.01^{* *}$ & $(0.00)$ & $0.01^{* *}$ & $(0.00)$ & $0.01^{* *}$ & $(0.00)$ & $0.02^{* *}$ & $(0.00)$ & $0.01^{* *}$ & $(0.00)$ & $0.02^{\star *}$ & $(0.00)$ \\
\hline \multicolumn{13}{|l|}{ Self assessed health (base-fair) } \\
\hline Healthy & $-3.82^{* *}$ & (0.08) & $-3.82^{\star *}$ & $(0.08)$ & $-3.80^{* *}$ & (0.08) & $-3.80^{* *}$ & (0.08) & $-3.83^{* *}$ & $(0.08)$ & $-3.78^{* *}$ & (0.08) \\
\hline Unhealthy & $5.18^{* *}$ & (0.13) & $5.19^{* *}$ & (0.13) & $5.15^{\star *}$ & $(0.13)$ & $5.17^{* *}$ & $(0.13)$ & $5.18^{* *}$ & (0.13) & $5.16^{* *}$ & (0.13) \\
\hline \multicolumn{13}{|l|}{ Shift working (base-non shiff) } \\
\hline Shift & $0.73^{* *}$ & (0.11) & $0.72^{\star *}$ & (0.11) & $0.73^{* *}$ & $(0.11)$ & $0.71^{* *}$ & (0.11) & $0.73^{* *}$ & $(0.11)$ & $0.72^{* *}$ & $(0.11)$ \\
\hline \multicolumn{13}{|l|}{ Sex (base-male) } \\
\hline Female & $1.22^{\star \star}$ & (0.08) & $1.50^{* \star}$ & $(0.08)$ & $1.21^{\star \star}$ & $(0.08)$ & $1.55^{\star \star}$ & $(0.08)$ & $1.20^{\star \star}$ & $(0.08)$ & $1.60^{* *}$ & (0.09) \\
\hline \multicolumn{13}{|l|}{ Marital status (base-single) } \\
\hline Married & $1.05^{\star *}$ & $(0.12)$ & $1.03^{* *}$ & $(0.12)$ & $1.04^{* *}$ & $(0.12)$ & $0.96^{* *}$ & $(0.12)$ & $1.06^{* *}$ & $(0.12)$ & $0.97^{* *}$ & (0.12) \\
\hline Divorced/separated & $1.53^{\star \star}$ & (0.23) & $1.45^{\star *}$ & $(0.23)$ & $1.52^{* *}$ & (0.23) & $1.40^{* *}$ & (0.23) & $1.54^{* *}$ & $(0.23)$ & $1.38^{* *}$ & (0.23) \\
\hline Widowed & $1.23^{\star *}$ & $(0.20)$ & $1.20^{* *}$ & $(0.20)$ & $1.21^{* *}$ & $(0.20)$ & $1.11^{* *}$ & $(0.20)$ & $1.24^{* \star}$ & $(0.20)$ & $1.11^{* *}$ & $(0.20)$ \\
\hline \multicolumn{13}{|l|}{ Employment (base-employed) } \\
\hline Unemployment & $1.46^{* \star}$ & (0.17) & $1.43^{\star *}$ & $(0.17)$ & $1.47^{* *}$ & $(0.17)$ & $1.43^{* *}$ & $(0.17)$ & $1.46^{* \star}$ & $(0.17)$ & $1.43^{* *}$ & $(0.17)$ \\
\hline Disability/retired/others & $0.53^{* \star}$ & $(0.14)$ & $0.59^{* *}$ & $(0.14)$ & $0.57^{* *}$ & (0.14) & $0.65^{* *}$ & $(0.14)$ & $0.52^{* *}$ & (0.14) & $0.68^{* *}$ & (0.14) \\
\hline Homemaker & 0.14 & $(0.11)$ & 0.20 & $(0.11)$ & 0.18 & $(0.11)$ & $0.24^{*}$ & $(0.11)$ & 0.15 & $(0.11)$ & $0.28^{*}$ & $(0.11)$ \\
\hline Student & $-0.56^{\star \star}$ & $(0.14)$ & $-0.40^{*}$ & $(0.14)$ & $-0.47^{*}$ & (0.14) & $-0.39^{*}$ & $(0.14)$ & $-0.56^{\star *}$ & $(0.14)$ & -0.27 & (0.14) \\
\hline Number of children in the household & $0.13^{*}$ & $(0.05)$ & $0.12^{*}$ & $(0.05)$ & $0.12^{*}$ & $(0.05)$ & $0.11^{*}$ & (0.05) & $0.13^{*}$ & (0.05) & $0.10^{*}$ & (0.05) \\
\hline \multicolumn{13}{|l|}{ Educational level (base $-<9$ years) } \\
\hline Some high school & -0.05 & $(0.12)$ & -0.07 & $(0.12)$ & -0.03 & $(0.12)$ & -0.08 & $(0.12)$ & -0.05 & $(0.12)$ & -0.08 & (0.12) \\
\hline High school graduate & $0.31^{*}$ & $(0.12)$ & $0.34^{*}$ & $(0.12)$ & $0.34^{*}$ & (0.12) & $0.41^{*}$ & (0.12) & $0.30^{*}$ & $(0.12)$ & $0.43^{*}$ & (0.12) \\
\hline Some college or higher & $0.53^{\star *}$ & $(0.14)$ & $0.62^{* *}$ & $(0.14)$ & $0.57^{* *}$ & $(0.14)$ & $0.71^{* *}$ & (0.14) & $0.52^{* \star}$ & (0.14) & $0.74^{* *}$ & (0.14) \\
\hline \multicolumn{13}{|l|}{ Income level (base - very low income) } \\
\hline Low income & -0.11 & (0.12) & -0.10 & (0.12) & -0.11 & (0.12) & -0.11 & (0.12) & -0.11 & (0.12) & -0.10 & (0.12) \\
\hline Middle income & -0.12 & $(0.14)$ & -0.10 & $(0.14)$ & -0.11 & $(0.14)$ & -0.09 & $(0.14)$ & -0.12 & $(0.14)$ & -0.07 & (0.14) \\
\hline High income & 0.10 & $(0.29)$ & 0.16 & $(0.28)$ & 0.15 & $(0.29)$ & 0.19 & $(0.28)$ & 0.11 & $(0.29)$ & 0.24 & (0.28) \\
\hline \multicolumn{13}{|l|}{ Health behaviours } \\
\hline Smoking & & & $0.71^{\star *}$ & $(0.10)$ & & & & & & & $0.28^{*}$ & $(0.10)$ \\
\hline Exercise & & & & & $-0.38^{* *}$ & $(0.08)$ & & & & & $-0.31^{*}$ & (0.08) \\
\hline Betel nut use & & & & & & & $1.39^{* *}$ & $(0.11)$ & & & $1.25^{* *}$ & (0.12) \\
\hline \multicolumn{13}{|l|}{ BMI (base $-<25$ ) } \\
\hline $25 \leqslant B M l<30$ & & & & & & & & & -0.16 & $(0.09)$ & $-0.21^{*}$ & (0.09) \\
\hline$B M I \geqslant 30$ & & & & & & & & & -0.02 & 10.21 & -0.08 & $(0.21)$ \\
\hline
\end{tabular}

Model 1 in table 2 shows the baseline model adjusted for age, shift work status, and general health perception. All the estimates were conditional on the clustering effect of the study design. In the baseline model, women scored an average of 1.25 points higher on the insomnia self assessment inventory than men.

Table 2 shows sex differences in insomnia scores before and after adding social role and SES variables to the baseline model. After adjusting for marital status, employment status, and number of children in the household, the sex differences in insomnia score decreased from 1.25 to $1.15,1.24$ and 1.24, respectively; thus, sleep quality of men is better even after adjusting for these factors. Compared with people who had never married, those who were currently married, divorced/ separated, or widowed tended to report higher levels of sleep disturbance. Among the ever married, insomnia was more severe among the divorced/separated than among the currently married in both sexes.

People who were unemployed and actively seeking work had the highest level of sleep disturbance compared with people in other employment categories; homemakers and people unemployed but not seeking work slept less well than the employed; students reported the lowest levels of insomnia. The number of children in the household was associated with increased levels of insomnia.

SES did not contribute to women's poor sleep quality, but the sex difference in insomnia score increased after adjusting for educational attainment. Sleep disturbance increased with increasing educational attainment. The relation between sleep disturbance and income level showed no specific trend.
Model 7 in table 2 is adjusted for all social variables and other control covariates. In this model, the average insomnia score for women was 1.22 points higher than for men.

Adjusting for smoking and betel nut use increased sex discrepancies in insomnia; sex differences decreased slightly after controlling for exercise and BMI (table 3). The coefficients for social factors did not change notieably when these behavioural variables were included; instead of mediating the association between social factors and insomnia, they seem to be independent predictors of sleep quality.

Table 4 shows the results of the subscale analysis. Compared with the employed, the group that was unemployed due to retirement, disability, or other reasons scored higher on the night time sleep disturbance subscale, but not the daytime sequelae subscale. In comparison with the employed, homemakers tended to report poorer night time sleep quality but less daytime sequelae. Higher level of education was associated with more daytime sequelae of insomnia, but not with night time sleep disturbance.

Social characteristics modified the effect of sex on sleep disturbance. The sex difference was most pronounced among the divorced/separated ( 2.52 points). It was $1.07,1.90$, and 2.09 points among the single, married, and widowed, respectively. Among employment categories, the sex gap in insomnia was largest among the unemployed ( 2.33 points) and least among students (0.66 points). Although number of children in the household was associated with higher levels of insomnia, there was no difference in its effect on women and men, even when the analysis was restricted to ever married people of child rearing age. Although educational attainment was positively associated with the severity of 
Table 4 Linear regression results showing sex differences in two subscales of insomnia: night time sleep disturbance compared with daytime sequelae

\begin{tabular}{|c|c|c|c|c|}
\hline \multirow[b]{2}{*}{ Parameter } & \multicolumn{2}{|c|}{ Night time sleep disturbance } & \multicolumn{2}{|c|}{ Daytime sequelae of poor sleep } \\
\hline & estimate & SE & estimate & SE \\
\hline Intercept & $12.73^{* *}$ & $(0.14)$ & $9.72^{* *}$ & $(0.14)$ \\
\hline \multicolumn{5}{|l|}{ Self assessed health (base-fair) } \\
\hline Healthy & $-1.55^{\star *}$ & $(0.04)$ & $-1.50^{* *}$ & $(0.04)$ \\
\hline \multicolumn{5}{|l|}{ Shift working (base-non-shift) } \\
\hline Shiff & $0.23^{* *}$ & $(0.05)$ & $0.32^{* *}$ & $(0.05)$ \\
\hline \multicolumn{5}{|l|}{ Sex (base-male) } \\
\hline Female & $0.69^{* *}$ & $(0.04)$ & $0.50^{* *}$ & $(0.04)$ \\
\hline \multicolumn{5}{|l|}{ Marital status (base-single) } \\
\hline Married & $0.50^{* *}$ & $(0.06)$ & $0.37^{\star *}$ & $(0.05)$ \\
\hline Divorced/separated & $0.71^{* *}$ & (0.11) & $0.44^{\star *}$ & $(0.10)$ \\
\hline Widowed & $0.67^{* *}$ & $(0.10)$ & $0.31^{* *}$ & (0.09) \\
\hline \multicolumn{5}{|l|}{ Employment (base-employed) } \\
\hline Unemployment & $0.76^{* *}$ & $(0.08)$ & $0.35^{\star *}$ & (0.07) \\
\hline Disability/retired/others & $0.56^{* *}$ & $(0.07)$ & -0.05 & $(0.06)$ \\
\hline Homemaker & $0.37^{\star *}$ & (0.05) & $-0.11^{*}$ & $(0.05)$ \\
\hline Student & $-0.17^{\star}$ & $(0.07)$ & $-0.21^{*}$ & $(0.06)$ \\
\hline \multicolumn{5}{|l|}{$\begin{array}{l}\text { Number of children in the household } \\
\text { Educational level (base }-<9 \text { years) }\end{array}$} \\
\hline Some high school & -0.03 & $(0.06)$ & 0.02 & (0.05) \\
\hline High school graduate & 0.05 & $(0.06)$ & $0.32^{* *}$ & $(0.05)$ \\
\hline \multicolumn{5}{|l|}{ Income level (base - very low income) } \\
\hline Low income & -0.08 & (0.05) & -0.01 & $(0.05)$ \\
\hline Middle income & -0.07 & $(0.06)$ & 0.03 & $(0.06)$ \\
\hline $\begin{array}{l}\text { High income } \\
\text { Health behaviour }\end{array}$ & 0.09 & $(0.13)$ & 0.08 & $(0.12)$ \\
\hline Smoking & -0.09 & $(0.05)$ & $0.21^{* *}$ & $(0.05)$ \\
\hline Exercise & $0.08^{*}$ & $(0.04)$ & $-0.27^{* *}$ & $(0.04)$ \\
\hline Betel nut use & $0.55^{\star *}$ & $(0.06)$ & $0.46^{* *}$ & $(0.05)$ \\
\hline \multicolumn{5}{|l|}{ BMI (base $-<25$ ) } \\
\hline $25 \leqslant \mathrm{BMl}<30$ & $-0.11^{*}$ & $(0.04)$ & $-0.08^{*}$ & (0.04) \\
\hline $\mathrm{BMI} \geqslant 30$ & -0.05 & $(0.10)$ & -0.05 & $(0.09)$ \\
\hline
\end{tabular}

insomnia, the effect was less prominent for women. Higher education had a positive impact on women's night time sleep quality but a negative impact for men (fig l). The interaction terms for sex and household income were not significant, showing that level of income did not modify sex discrepancy in sleep quality. The three way interaction between sex, SES, and family responsibilities was also not significant (data not shown).

\section{DISCUSSION}

Our findings suggest that social factors cannot fully explain the sex difference in sleep disturbance. While the sex discrepancy narrowed after controlling for marital status, employment conditions, and number of children in the household, women's sleep quality remained significantly

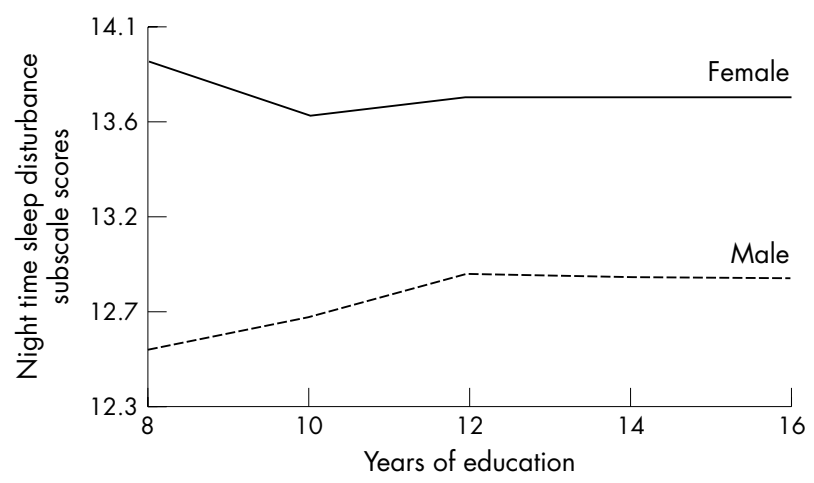

Figure 1 Interaction between sex and educational attainment. worse than men's sleep quality. Even though women were over-represented among the less educated and economically deprived, these disadvantaged socioeconomic conditions did not translate into more sleep disturbance. Health behaviours and obesity did not mediate the association between social factors and insomnia but were independent predictors of sleep quality.

There are several explanations for our findings-firstly, the sex difference in insomnia may be largely determined by inherent biological differences while socio-contextual factors play only a minor part. However, the fact that sleep disturbance is a sensitive indicator of life stress suggests that

\section{Key points}

- There is a consistent sex disparity in insomnia, with women reporting a higher prevalence.

- Sex related social roles partly explain the sex discrepancy in insomnia.

- The sex gap in insomnia was greater among the unemployed and divorced/separated.

- Higher number of children in the family was associated with higher levels of insomnia; but women's and men's sleep was equally affected by this variable.

- Higher educational attainment was associated with better night time sleep quality among women. By contrast, men with higher degrees of education were more likely to have night time sleep disturbances. 
factors other than individual biology shape sleep quality. ${ }^{20} 21$ Secondly, the observed sex difference may be statistically but not clinically significant, particularly because the insomnia self assessment inventory is not a diagnostic tool for clinical insomnia. Thirdly, the categories of social roles and socioeconomic groups may not truly reflect social contexts, burdens, or the demands of these social circumstances. ${ }^{22}$ The true quality of individual roles and the availability of socioeconomic resources for any given status may not have been well captured.

Regardless of marital status, women had higher average levels of insomnia. Consistent with previous reports, the sex gap is largest among the divorced and separated, ${ }^{23}{ }^{24}$ which may be related to the stress associated with single parenthood, loss of economic support, and the social stigma attached to divorce or separation. ${ }^{22}$

The increased risk for sleep disturbance among unemployed people is also consistent with previous findings. ${ }^{25}$ The large sex discrepancy in insomnia among the unemployed shows that the impact of unemployment on sleep quality is larger among women, especially married women. This may be related to increased difficulty in job seeking because of institutional sex discrimination, and greater financial threats for unemployed women because of their childcare responsibilities. Another possibility is that women who identified themselves as being unemployed were more likely to belong to households with lower earnings, showing a greater need for paid employment. Their strained domestic circumstances may have also contributed to their insomnia.

In contrast with studies from other countries that found homemakers had more insomnia complaints, ${ }^{23} 24$ our analysis found that the insomnia scores among homemakers did not differ from those who were employed once other relevant covariates were taken into account. None the less, homemakers tended to report more night time sleep difficulty but less daytime sequelae. This shows that different mechanisms may determine sleep disturbance in employed persons compared with homemakers. Specifically, increased night time sleep disturbance among homemakers may be the consequence of life stresses associated with their role (for example, low status, low reward), whereas the daytime sequelae of poor sleep among the employed may derive from inadequate sleep because of long working hours. The other explanation is that daytime tiredness arising from insomnia may have readily observable consequences for employed persons, whereas for homemakers, the consequences may be limited to the domestic sphere and less visible.

Students had the smallest sex gap in sleep disturbance (0.93 point) after controlling for other characteristics. In Taiwanese society, attaining high education is encouraged and being a student is esteemed. Furthermore, students are often entitled to financial support from family members and are freed from family responsibilities.

In agreement with previous studies, more children in the family was associated with higher levels of insomnia ${ }^{26}{ }^{27}$ but

\section{Policy implications}

- Insomnia, a widespread problem in many societies, needs to be tackled through a variety of approachesnot just individual behaviour change (such as smoking cessation or exercise), but also through modifying the social context (patterns of shift work, support for child care).

- Additional research is needed to understand, and intervene on, sex discrepancies in insomnia. men's and women's sleep were equally affected. This finding may result from using the number of children in the household as a proxy for childcare responsibility. In our sample, the variability was quite limited given an average number of children among the ever-married group of 1.58 $(\mathrm{SD}=1.24)$ and only $5.6 \%$ with more than three children. Furthermore, we lacked information on the age of children, which is probably related to their impact on parental sleep quality. Most importantly, our proxy variable could not capture the qualitative differences in care giving. The lack of a sex effect according to number of children may also reflect the three generational family structure prevalent in Taiwan, in which grandparents share childcare responsibilities. This extended family structure may buffer the effect of additional children on the sleep quality of both women and men.

In sharp contrast with other research on the association between SES and insomnia, ${ }^{28}$ we did not find an increased risk of sleep disturbance among those of lower SES. In contrast, levels of insomnia increased with increased level of education and there was no consistent association with household income. Thus sex distribution of SES in Taiwan (with women occupying lower SES positions) could not explain the higher level of sleep disturbance in women. Taiwan has been described as a society where high economic growth, fair distribution of income, and population health have been achieved concurrently, ${ }^{29}$ and the comparatively equal distribution of income may explain the lack of an income-insomnia relation.

The effects of SES differed according to the insomnia subscales. Educational attainment was positively associated with the severity of daytime sequelae but had no impact on night time sleep disturbance. This suggests that the patterns of insomnia associated with higher levels of education may be the consequence of inadequate sleep, rather than difficulty in sleep initiation or maintenance. The findings are consistent with the industrial employment sector that is similar to the "lifetime employment" system in Japan. Higher status employees (often with higher educational attainment) are strongly attached to their company, which they view as "family", and this leads to long working hours. ${ }^{30}$

The sex gap in the full insomnia inventory did not change significantly with the addition of an interaction term between SES and sex. However, the subscale analysis showed an opposite effect of education on night time sleep quality by sex. Specifically, people with fewer years of education had a wider gender gap in night time sleep quality than did people with higher educational attainment.

A novel aspect of this study was its focus on the broader social context, which directs attention away from blaming "vulnerable women" to examining the social and cultural determinants of insomnia among women. An important advantage of the social trend survey is its high coverage of citizens living in Taiwan. Because the government's household registration system is institutionalised, all citizens were covered by the sampling frame, and the survey is generally representative. In addition, face to face interviews led to limited missing data and ensured that illiterate people were included.

A number of limitations should be considered in interpreting these results. Firstly, causal inferences cannot be drawn because of the cross sectional nature of the study. Secondly, the range of variables that could be analysed was limited. For example, baseline depression, anxiety, and use of psychiatric drugs were not available. Furthermore, the measurement of the outcome variable, insomnia, was based on self assessment. No other objective measure was used to validate the self evaluation although the reliability and validity of the measure was good and several other studies have showed 
the value of self reported inventories in assessing sleep quality and predicting health outcomes. ${ }^{4}$

Our study suggests that social factors partly influence sleep quality and sex inequality in insomnia. However, the persistence of the sex gap suggests that further exploration is warranted using a more detailed sociological approach.

\section{Authors' affiliations}

Y-Y Chen, Taipei City Psychiatric Centre, Xinyi District, Taipei City, Taiwan

Y-Y Chen, I Kawachi, S V Subramanian, D Acevedo-Garcia, Department of Society, Human Development and Health, Harvard School of Public Health, USA

Y-J Lee, National Taiwan University, College of Medicine, Taiwan

Funding: none.

Conflicts of interest: none declared.

\section{APPENDIX}

\section{INSOMNIA SELF ASSESSMENT INVENTORY}

1. I had difficult falling asleep

2. It took me more than an hour to fall asleep

3. I woke up more than three times during the night

4. If I woke up, it took me a long time to fall back sleep

5. I woke up too early in the morning

6. I worried about being able to sleep well

7. (I drank alcohol to help me fall asleep)-eliminated from the analysis

8. I had restlessness or twitching feelings in my legs when lying down

9. I had difficult arising in the morning

10. I woke up feeling tired

11. My sleep was un-refreshing

12. I didn't sleep as long as I needed to despite enough time in bed.

13. My sleep left me fatigued during the day

\section{REFERENCES}

1 Walsh JK, Uestuen TB. Prevalence and health consequences of insomnia. Sleep 1999;22(suppl):S427-36.

2 Li RHY, Wing YK, Ho SC, et al. Gender differences in insomnia-a study in the Hong Kong Chinese population. J Psychosom Res 2002;53:601-9.

3 Doi $Y$, Minowa $M$, Okawa $M$, et al. Prevalence of sleep disturbance and hypnotic medication use in relation to sociodemographic factors in the general Japanese adult population. J Epidemiol 2000;10:79-86.
4 Culebras A. Insomnia. In: Sleep disorder. Boston: Butterworth-Heinemann, 1996.

5 Reyner LA, Horne JA, Reyner A. Gender- and age-related differences in sleep determined by home-recorded sleep logs and actimetry from 400 adults. Sleep 1995; 18:127-34.

6 Holmshaw J, Hillier S. Gender and culture: a sociological perspective to mental health problems in women. In: Kohen D, ed. Women and mental health. Philadelphia: Routledge, 2000:39-64.

7 Manber R, Armitage R. Sex, steroids, and sleep: a review. Sleep 1999:22:540-55.

8 Jones CR, Czajkowski L. Evaluation and management of insomnia in menopause. Clin Obstet Gynecol 2000;43:184-97.

9 Polo-Kantola P, Saaresranta T, Polo O. Aetiology and treatment of sleep disturbances during perimenopause and postmenopause. CNS Drugs 2001;15:445-52

10 Campbell SS, Gillin JC, Kripke DF, et al. Gender differences in the circadian temperature rhythms of healthy elderly subjects: relationships to sleep quality. Sleep 1989;12:529-36.

11 Manber R, Armitage R. Sex, steroids, and sleep: a review. Sleep 1999:22:540-55.

12 Hume KI, Van F, Watson A. A field study of age and gender differences in habitual adult sleep. J Sleep Res 1998;7:85-94.

13 Rediehs MH, Reis JS, Creason NS. Sleep in old age: focus on gender differences. Sleep 1990;13:410-24.

14 Lindberg $\mathbf{E}$, Janson C, Gislason T, et al. Sleep disturbances in a young adult population: can gender differences be explained by differences in psychological status? Sleep 1997;20:381-7.

15 European Commission Directorate-General for Employment and Social Affairs. Gender use of time: three European studies. Luxembourg: Office for Official Publications of the European Communities, 2000.

16 Directorate General of Budget Accounting and Statistics. National Statistics 2000. http://www.stat.gov.tw/main.htm (accessed 20 May 2004).

17 Directorate General of Budget Accounting and Statistics. Report of social trend survey: health and security. Taipei: Directorate General of Budget Accounting and Statistics, Executive Yuan, 2002.

18 World Health Organisation. Worldwide project on sleep and health. Geneva: International Foundation for Mental Health and Neuroscience, 2001.

19 American Psychiatric Association. Diagnostic and statistical manual of mental disorders. 4th ed. Washington DC: American Psychiatric Association, 1994.

20 Partinen M. Sleep disorders and stress. J Psychosom Res 1994;38:89-91.

21 Cartwright RD, Wood E. Adjustment disorders of sleep: the sleep effects of a major stressful event and its resolution. Psychiatry Res 1991;39:199-209.

22 Sachs-Ericsson N, Ciarlo JA. Gender, social roles, and mental health: an epidemiological perspective. Sex Roles 2000;43:605-28.

23 Ford DE, Kamerow D. Epidemiologic study of sleep disturbances and psychiatric disorders: an opportunity for prevention? JAMA 1989:262:1479-84

24 Bixler EO, Kales A, Soldatos CR, et al. Prevalence of sleep disorders in the Los Angeles metropolitan area. Am J Psychiatry 1979;136:1257-62.

25 Hyyppa MT, Kronholm E, Alanen E. Quality of sleep during economic recession in Finland: a longitudinal cohort study. Soc Sci Med 1997:45:731-8.

26 Gerald LB. Mental health outcomes among women in caregiving roles: wlder care versus child care. Dissertation Abstracts International 58. USA: University Microfilms International, 1998:3737.

27 Naerde A, Tambs K, Mathiesen KS, et al. Symptoms of anxiety and depression among mothers of pre-school children: effect of chronic strain related to children and child-taking. J Affect Disord 2000;58:181-99.

28 Moore PJ, Adler NE, Williams DR, Jackson JS. Socioeconomic status and health: the role of sleep. Psychosom Med 2002;64:337-44.

29 Siddiqi A, Hertzman C. Economic growth, income equality, and population health among the Asian Tigers. Int J Health Serv 2001;31:323-33.

30 Clark R. The Japanese company. New Haven: Yale University Press, 1979. 